\title{
Article
}

\section{LAG-3 Blockade with Relatlimab (BMS-986016) Restores Anti-Leukemic Responses in Chronic Lymphocytic Leukemia}

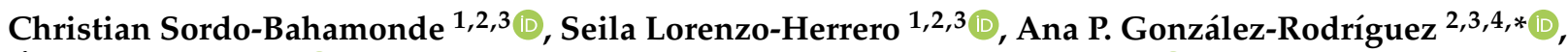 \\ Ángel R. Payer ${ }^{2,3,4}\left(\mathbb{D}\right.$, Esther González-García ${ }^{5}$, Alejandro López-Soto ${ }^{2,3,6}$ and Segundo Gonzalez ${ }^{1,2,3, *(1)}$ \\ 1 Department of Functional Biology, Immunology, Universidad de Oviedo, 33006 Oviedo, Spain; \\ Christiansbl87@gmail.com (C.S.-B.); seilalorenzoherrero@gmail.com (S.L.-H.) \\ 2 Instituto Universitario de Oncología del Principado de Asturias (IUOPA), 33006 Oviedo, Spain; \\ apayer.angel@gmail.com (Á.R.P.); lopezsalejandro@uniovi.es (A.L.-S.) \\ 3 Instituto de Investigación Sanitaria del Principado de Asturias (ISPA), 33011 Oviedo, Spain \\ 4 Department of Hematology, Hospital Universitario Central de Asturias (HUCA), 33011 Oviedo, Spain \\ 5 Department of Hematology, Hospital de Cabueñes, 33203 Gijón, Spain; esthergongar@yahoo.es \\ 6 Department of Biochemistry and Molecular Biology, University of Oviedo, 33006 Oviedo, Spain \\ * Correspondence: anapilargonzalez@gmail.com (A.P.G.-R.); segundog@uniovi.es (S.G.)
}

\section{check for}

updates

Citation: Sordo-Bahamonde, C.; Lorenzo-Herrero, S.; González-

Rodríguez, A.P.; Payer, Á.R.; González-García, E.; López-Soto, A.; Gonzalez, S. LAG-3 Blockade with Relatlimab (BMS-986016) Restores Anti-Leukemic Responses in Chronic Lymphocytic Leukemia. Cancers 2021, 13, 2112. https://doi.org/10.3390/ cancers13092112

Academic Editor: Matthew J. Olnes

Received: 23 March 2021

Accepted: 22 April 2021

Published: 27 April 2021

Publisher's Note: MDPI stays neutral with regard to jurisdictional claims in published maps and institutional affiliations.

Copyright: (c) 2021 by the authors. Licensee MDPI, Basel, Switzerland. This article is an open access article distributed under the terms and conditions of the Creative Commons Attribution (CC BY) license (https:// creativecommons.org/licenses/by/ $4.0 /)$.
Simple Summary: Patients with chronic lymphocytic leukemia (CLL), the most frequent B cell malignancy in western countries, develop a progressive immunosuppression, leading to diminished anti-tumor immunity. Within the last years, immune checkpoint blockade has revolutionized anticancer therapies. Nonetheless, patients with CLL failed to achieve clinical benefits from therapies targeting widely-studied checkpoints such as PD-1/PD-L1 or CTLA-4. In this context, our results provide new insights about LAG-3 expression dysregulation in CLL and its role promoting tumor escape. Our data suggest that increased LAG-3 expression on leukemic cells correlates with shorter time to treatment and poor outcome in CLL. Moreover, treatment with relatlimab, a novel anti-LAG-3 blocking monoclonal antibody currently under clinical trial for different solid and hematological malignancies including CLL, restored, at least in part, NK and T cell-mediated anti-tumor responses. Altogether, our data provide the rationale to further investigate the role of LAG-3 in the pathogenesis of CLL.

Abstract: The inclusion of monoclonal antibodies targeting immune checkpoints such PD-1/PD-L1 or CTLA-4 has revolutionized the landscape of anti-cancer therapy. However, PD-1 and CTLA-4 blockade failed to achieve clinical benefit in CLL, thus attention has been focused on emerging checkpoints in this malignancy. LAG-3 is an immune checkpoint receptor that negatively regulates $\mathrm{T}$ cell-mediated responses by inducing an hyporesponsive state, thus promoting tumor escape. Patients with chronic lymphocytic leukemia (CLL) develop a profound immune suppression that leads to lessened immunosurveillance and increased risk of developing a secondary neoplasia. In the study herein, we report the profound dysregulation of LAG-3 on leukemic cells in CLL. Likewise, natural killer (NK) and T cells showed increased LAG-3 expression, hence suggesting a role for this checkpoint in CLL-associated immunosuppression. High LAG-3 expression, as well as high levels of soluble LAG-3 (sLAG-3), correlated with adverse cytogenetics and poor outcome in patients with CLL, highlighting the clinical relevance of this immune checkpoint. Treatment of peripheral blood mononuclear cells (PBMCs) from patients with CLL with relatlimab, a new anti-LAG-3 blocking antibody currently evaluated in numerous clinical trials, depleted leukemic cells and restored NK cell- and T cell-mediated responses. Moreover, combination of LAG-3 with the immunomodulatory drug (IMiD) lenalidomide significantly increased IL-2 production by T cells and antibody-dependent cytotoxicity (ADCC) mediated by NK cells. Altogether, these data provide new insights into the potential anti-leukemic effects of relatlimab, currently in clinical trials in CLL, and provides the rationale to further investigate its combination with IMiDs for the management of hematological malignancies. 
Keywords: chronic lymphocytic leukemia; CLL; LAG3; relatlimab; immunotherapy; immune checkpoint; ICB; NK cell; immunosurveillance

\section{Introduction}

Chronic lymphocytic leukemia (CLL), the most common B cell malignancy in adulthood, is characterized by a progressive accumulation of clonal mature B cells in blood, lymph nodes and bone marrow. T and natural killer (NK) cells have been shown to orchestrate antileukemic immune responses, hence playing a significant role in the pathogenesis of CLL [1-3]. However, CLL progression is associated with progressive immunosuppression, leading to attenuated immunosurveillance and diminished antitumor responses associated with an exhausted phenotype or unresponsive state of $\mathrm{T}$ and NK cells $[4,5]$. Thus, $\mathrm{T}$ and NK cells in CLL typically exhibit upregulation of inhibitory checkpoints, impaired proliferative capacity, reduced cytokine production and weak cytotoxicity against tumor cells [6-9]. Restoring $\mathrm{T}$ and NK cell-mediated responses through checkpoint blockade has become a promising therapeutic strategy in a wide variety of solid tumors and hematological malignancies [10]. However, immune checkpoint blockade (ICB)-based therapy using monoclonal antibodies (mAbs) against PD-1 and CTLA-4 failed to achieve clinical benefit in CLL [11,12]. In this context, exploring emerging checkpoint molecules as potential novel therapeutic targets in CLL has attracted attention in the last years.

Lymphocyte activation gene 3 (LAG-3) is an inhibitory immune checkpoint receptor that belongs to the immunoglobulin superfamily with approximately $20 \%$ amino acid homology with CD4. LAG-3 is expressed on activated and exhausted T and NK cells, as well as on B cells, dendritic cells, and regulatory $\mathrm{T}$ (Treg) cells [13-16]. Upon engagement with MHC class II molecules, or its newly described ligand, fibrinogen-like protein 1 (FGL1), LAG-3 negatively regulates $\mathrm{T}$ and NK cells, thereby promoting tumor escape likely by promoting exhaustion in combination with other checkpoints such as PD1 [17-19]. Hence, dysregulated LAG-3 expression has been reported to negatively correlate with clinical outcome in a wide variety of cancers, including some of hematological origin, including CLL, follicular lymphoma (FL), diffuse large B-cell lymphoma (DLBCL) or acute myeloid leukemia (AML) [20-22]. LAG-3 signaling impairs T cell proliferation, cytokine production and cytolytic function while its expression on Tregs may promote immunosuppression [23-28]. Despite the functional consequence of LAG-3 blockade has extensively been studied in T cells, it has poorly been explored in NK cell function, although LAG-3 blockade failed to increase NK cell-mediated cytotoxicity in previous studies [29-31].

Relatlimab (BMS-986016, Bristol-Myers Squibb, New York, NY, USA), a human $\operatorname{IgG}_{4}$ anti-LAG3 blocking $\mathrm{mAb}$ is currently being evaluated in several phase I and II/III clinical trials in solid tumors and hematological malignancies, including CLL (ClinicalTrials.gov Identifier: NCT02061761), alone or in combination with anti-PD-1/PD-L1 blocking mAbs [32].

Herein, we provide new insights into the potential role of relatlimab in the restoration of $\mathrm{T}$ and NK cell-mediated responses in patients with CLL. Our data confirm the profound dysregulation of LAG-3 in leukemic cells, and also unveil a significant dysregulation of LAG-3 on NK and T cells. Importantly, this dysregulation correlates with adverse genetic and cytogenetic features of patients with CLL and it is associated with poor outcome. LAG-3 inhibitory signaling disruption with relatlimab significantly enhanced antitumor responses mediated by NK and T cells in CLL, further supporting the use of anti-LAG-3 $\mathrm{mAbs}$ in the treatment of CLL. 


\section{Materials and Methods}

\subsection{Patient's Samples}

Peripheral blood samples from 61 consecutive non-treated patients with CLL (Table 1) were obtained from Hospital Universitario Central de Asturias and Hospital de Cabueñes according to the Declaration of Helsinki with the approval of the local ethics committee (Comité de Ética de la Investigación del Principado de Asturias, case-19042016). Clinical analyses were performed according to International workshop on CLL guidelines criteria. Samples from healthy donors (HD) $(n=20)$ were provided by Centro Comunitario de Sangre y Tejidos de Asturias. FISH analysis for chromosome 13q deletion, 11q deletion, $17 \mathrm{p}$ deletion and trisomy 12 was performed. Variable region of the immunoglobulin heavy chain IGHV mutation status was characterized by direct sequencing method, and patients were categorized as unmutated (IGHV 98\% germline homology) or mutated ( $98 \%$ homology). Twenty patients showed clinical progression and required therapeutic intervention after sample collection. The median follow-up from diagnosis of patients was 71 months.

Table 1. Clinical characteristics of patients with CLL included in the study.

\begin{tabular}{|c|c|c|}
\hline Patients & Patients $(n=61)$ & $\%$ \\
\hline \multicolumn{3}{|l|}{ Age } \\
\hline Years (mean) & 74.8 & \\
\hline \multicolumn{3}{|l|}{ Sex } \\
\hline Female & 24 & 39.3 \\
\hline Male & 37 & 60.6 \\
\hline \multicolumn{3}{|l|}{ Rai Stage } \\
\hline 0 & 35 & 57.3 \\
\hline I-II & 18 & 29.5 \\
\hline III-IV & 8 & 13.1 \\
\hline \multicolumn{3}{|l|}{ Binet Stage } \\
\hline $\mathrm{A}$ & 49 & 80.3 \\
\hline $\mathrm{B}$ & 6 & 9.8 \\
\hline $\mathrm{C}$ & 6 & 9.8 \\
\hline \multicolumn{3}{|c|}{ Cytogenetic abnormalities (FISH) } \\
\hline No alterations & 26 & 42.6 \\
\hline $\operatorname{del}(13 q)$ & 18 & 29.5 \\
\hline $\operatorname{del}(11 q)$ & 1 & 1.6 \\
\hline $\operatorname{del}(17 p)$ & 3 & 4.9 \\
\hline Trisomy 12 & 5 & 8.1 \\
\hline Complex karyotype & 8 & 13.1 \\
\hline \multicolumn{3}{|l|}{ IGHV status } \\
\hline Mutated & 37 & 60.6 \\
\hline Unmutated & 13 & 21.3 \\
\hline Undetermined & 11 & 18 \\
\hline \multicolumn{3}{|l|}{ Progression } \\
\hline Stable disease & 41 & 67.2 \\
\hline Progressive disease & 20 & 32.7 \\
\hline
\end{tabular}

Variable region of the immunoglobulin heavy chain.

Peripheral blood mononuclear cells (PBMCs) from patients with CLL and HD were isolated by ficoll density gradient centrifugation ((Histopaque ${ }^{\circledR}-1077$, Sigma-Aldrich, St. Louis, MO, USA) and used fresh. PBMCs were cultured in RPMI 1640 (Lonza, Basilea, Switzerland) complete medium (supplemented with $10 \%$ heat-inactivated fetal bovine serum, $1 \mathrm{mM}$ sodium pyruvate, $2 \mathrm{mM}$ L-glutamine, $100 \mathrm{U} / \mathrm{mL}$ penicillin and $10 \mu \mathrm{g} / \mathrm{mL}$ 
streptomycin) at $37^{\circ} \mathrm{C}$ and $5 \% \mathrm{CO}_{2}$. CLL-derived cell line MEC-1 was obtained from the ATCC and cultured in Iscove's Modified Dulbecco's Medium (IMDM) supplemented as described above.

\subsection{Immune Subset Identification and Phenotypical Analyses}

Phenotypical analyses of leukemic cells, B lymphocytes and T and NK cells from patients and HD were performed by flow cytometry. The following antibodies were employed: anti-CD19-APC, anti-CD4-CFblue, anti-CD8-APC750 and anti-CD3-PE (Immunostep, Salamanca, Spain), anti-CD3-FITC and anti-CD56-APC (both from Cytognos, Salamanca, Spain). Leukemic cells were identified as CD19+. NK cells were defined as CD56+CD3-. Total T lymphocytes (CD3+CD56-) as well as Thelper (CD3+CD4+) and cytotoxic $(\mathrm{CD} 3+\mathrm{CD} 8+)$ subpopulations were also identified. LAG-3 expression was evaluated using anti-LAG3-PE (clone 7H2C65, Biolegend, San Diego, CA, USA). Data was analyzed in a Cytoflex $\mathrm{S}$ flow cytometer and CytExpert 2.3 software (Beckman Coulter, Brea, CA, USA).

\subsection{Absolute Cell Count Assay}

PBMCs from patients with CLL were treated with the blocking anti-LAG-3 mAb relatlimab (BMS-986016, kindly provided by Bristol-Myers Squibb), or control IgG $(10 \mu \mathrm{g} / \mathrm{mL})$ for $72 \mathrm{~h}$ or a week, alone or in combination with $10 \mu \mathrm{M}$ lenalidomide (LND) (Santa Cruz Biotechnology, Dallas, TX, USA). At the indicated timepoint, leukemic cells were identified with anti-CD19-APC staining and an equal volume of PKH26 reference microbeads (Sigma-Aldrich) was added to each condition. A total of 5000 reference microbeads were acquired, and absolute leukemic cell count was determined by flow cytometry. Percentage of leukemic cell depletion was normalized to control.

\subsection{Proliferation Assay}

PBMCs obtained from patients were stained with $1 \mu \mathrm{M}$ 5,6-carboxyfluorescein diacetate succinimidyl ester (CFSE, Sigma Aldrich) and cultured in the presence or absence of anti-LAG-3 blocking antibody or control IgG for $72 \mathrm{~h}$. Culture media was supplemented with $50 \mathrm{U} / \mathrm{mL}$ IL-2 (ORF Genetics, Kópavogu, Iceland). Immune subsets were identified as mentioned above and percentage of proliferating cells was analyzed by flow cytometry.

\subsection{In Silico Analysis}

LAG3 mRNA expression was evaluated from publicly available RNAseq data from the Gene Expression Omnibus repository (GEO). GSE22762, GSE4392, GSE112953 and GSE1590 datasets were analyzed using the online webtool ShinyGeo (https:/ / gdancik. shinyapps.io/shinyGEO/, accessed on 8 January 2020) [33]. The prognostic value of LAG3 axis was evaluated using Prediction of Clinical Outcomes from Genomic Profiles (PRECOG) tool. Z-scores for each gene studied were obtained from the PRECOG website and a heatmap was drawn using GraphPad Prism 8.0 software (Biosoft, San Diego, CA, USA) [34]. The mutational landscape regarding LAG3 expression was evaluated using cBioportal v3.6.12 (https:/ / www.cbioportal.org/ accessed on 12 December 2019) publicly available data [35].

\subsection{Evaluation of Soluble LAG-3 in Serum Samples}

Levels of soluble LAG-3 (sLAG-3) were evaluated in serum samples from 28 patients with CLL and 12 HD by ELISA (RayBiotech, Peachtree Corners, GA, USA) following the manufacturer's instructions.

\subsection{Intracellular Protein Staining}

To assess the effect of relatlimab on cytokine production, PBMCs from patients with CLL were treated with anti-LAG-3 blocking mAb or control IgG $(10 \mu \mathrm{g} / \mathrm{mL})$ alone or in combination with lenalidomide $(10 \mu \mathrm{M})$ or DMSO for $72 \mathrm{~h}$. Then, immune subset 
identification followed by intracellular cytokine staining and flow cytometry analyses were performed as previously described by our group [36]. Briefly, treated PBMCs were stimulated with $50 \mathrm{nM}$ PMA and $1 \mu \mathrm{g} / \mathrm{mL}$ ionomycin for $4 \mathrm{~h}$. After $1 \mathrm{~h}$ incubation with PMA/ionomycin, brefeldin A (Biolegend) was added. Afterwards, BD Cytofix/Cytoperm Fixation/Permeabilization Kit (BD Biosciences, BD Biosciences, San Jose, CA, USA) was employed according to the manufacturer's instructions. Percentage of positive T lymphocytes for IL-2 (clone MQ1-17H12, Biolegend), IFN- $\gamma$ (clone 4S.B3, Biolegend) and TNF- $\alpha$ (clone Mab11, Biolegend) staining was determined. For evaluation of intracellular Bcl-2 protein levels, PBMCs from patients were treated with relatlimab or control IgG $(10 \mu \mathrm{g} / \mathrm{mL})$ for $72 \mathrm{~h}$ or 7 days. Thereupon, cells were stained with anti-CD19-APC for leukemic cell identification and BD Cytofix/Cytoperm Kit was used to fix and permeabilize cells. Bcl-2 expression was evaluated using anti-Bcl-2-PE (clone 100, Biolegend).

\subsection{Determination of NK Cell-Mediated Cytotoxicity}

NK cell-mediated cytotoxicity and antibody-dependent cellular cytotoxicity (ADCC) was evaluated by calcein-AM staining as previously described by our group [37]. Total PBMCs from patients with CLL were treated with relatlimab or control IgG $(10 \mu \mathrm{g} / \mathrm{mL})$ for $72 \mathrm{~h}$. MEC-1 target cell line was stained with $10 \mu \mathrm{M}$ calcein-AM (Biolegend) according to manufacturer's instructions and co-cultured with PBMCs at a 25:1 effector: target (E:T) ratio for $4 \mathrm{~h}$ in a 96-well U-bottom plate, and calcein release was measured on a Varioskan ${ }^{\mathrm{TM}}$ LUX multimode microplate reader. For ADCC assays, MEC- 1 cell line was pre-treated with $10 \mu \mathrm{g} / \mathrm{mL}$ rituximab or control IgG for $30 \mathrm{~min}$.

\subsection{Statistics}

Statistical analyses were performed using GraphPad Prism 8.0 software (Biosoft). The relationship between continuous and categorical prognostic variables was evaluated by Mann-Whitney $U$-test, whereas intra-group comparisons were performed by Wilcoxon Matched-Pairs Signed Ranks test. For time-to-event analysis, Kaplan-Meier curves were plotted, and each group was compared by long-rank test. Relationship between patient characteristics and survival was evaluated by univariate Cox proportional hazards models using SPSS v23.0 software; $p$-values of $\leq 0.05$ were considered statistically significant.

\section{Results}

\subsection{Surface and Soluble LAG-3 Expression Are Increased in CLL}

LAG-3 surface expression was evaluated in PBMCs from patients with CLL $(n=61)$ and HD $(n=20)$ by flow cytometry (Figure 1A). While no significant differences in the percentage of LAG-3 expressing B cells were observed, the level of LAG3 surface expression was found to be significantly upregulated on leukemic cells from patients with CLL (mean fluorescence intensity (MFI) \pm standard error of mean (SEM): $426.4 \pm 83.5$ vs. $142.7 \pm 10.1, p=0.0012$ ) (Figure 1B,C). In line with this, sLAG3 levels were highly increased in serum samples from patients compared to HD $(2445 \mathrm{ng} / \mathrm{mL} \pm 741 \mathrm{ng} / \mathrm{mL}$ vs. $13.05 \mathrm{ng} / \mathrm{mL} \pm 6.3 \mathrm{ng} / \mathrm{mL}, p<0.0001$ ) (Figure 1D). Remarkably, levels of sLAG-3 positively correlated with surface expression and percentage of LAG-3-+ leukemic cells (Spearman's rank test $p=0.002$ and $p=0.006$, respectively). In silico analysis of publicly available data from GEO database revealed that treatment of patients with lenalidomide, but not rituximab or fludarabine-chlorambucil regimen, significantly increased LAG3 mRNA expression in leukemic cells $(p=0.0024)$ (Figure 1E). Altogether these data confirm the profound dysregulation of LAG-3 on leukemic cells and provides the rationale for the investigation of LAG-3 blockade in combination with the immunomodulatory drug lenalidomide [22]. 
A
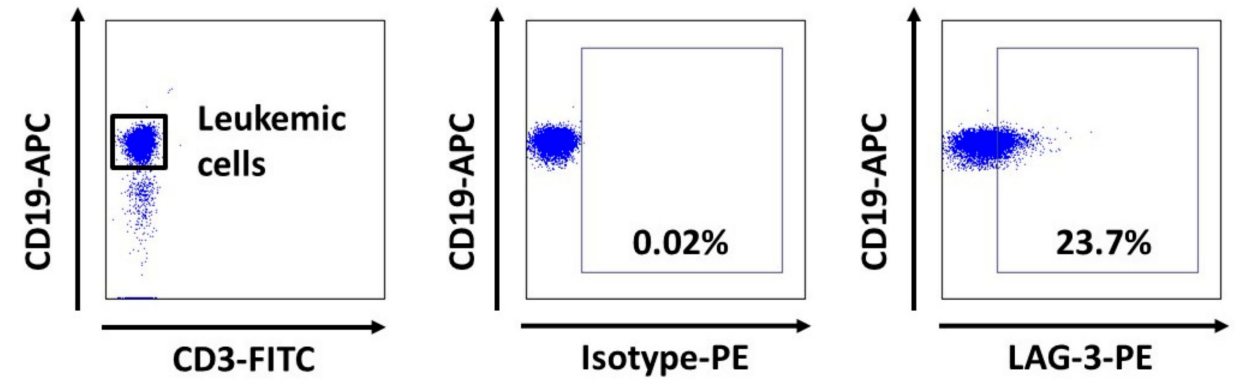

B

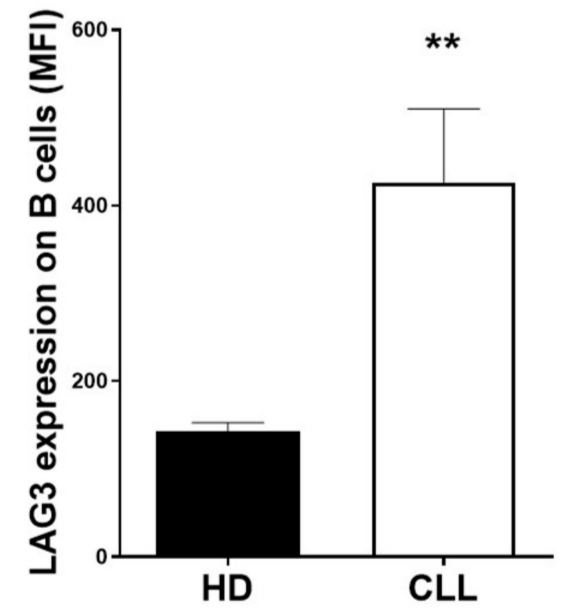

D

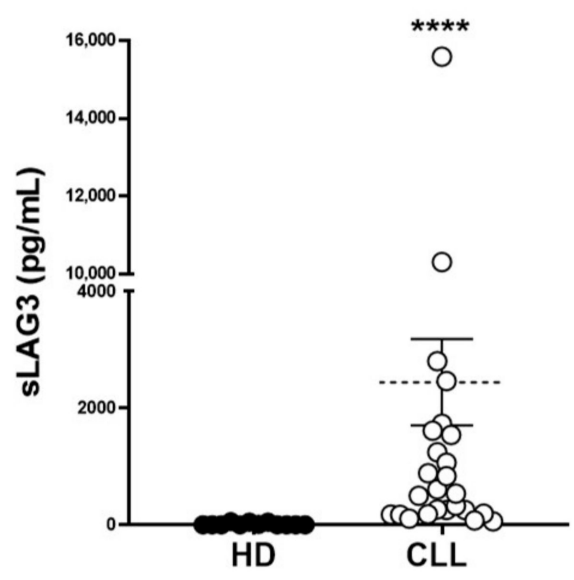

C

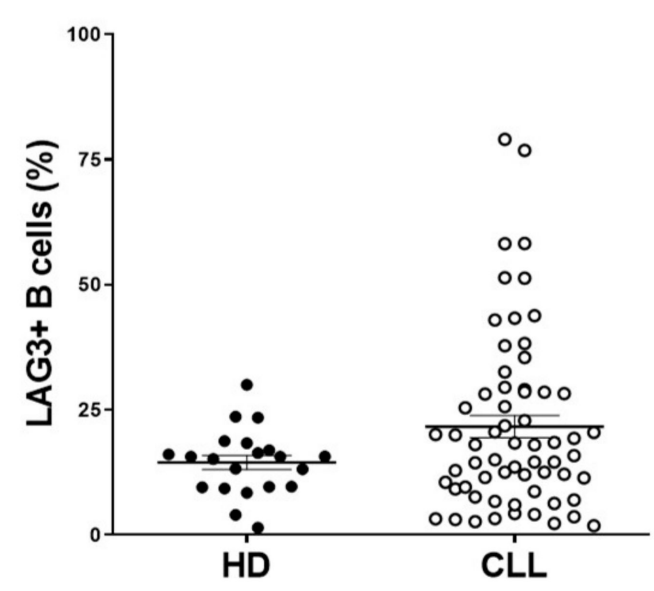

E Before Treatment $\square$ After Treatment

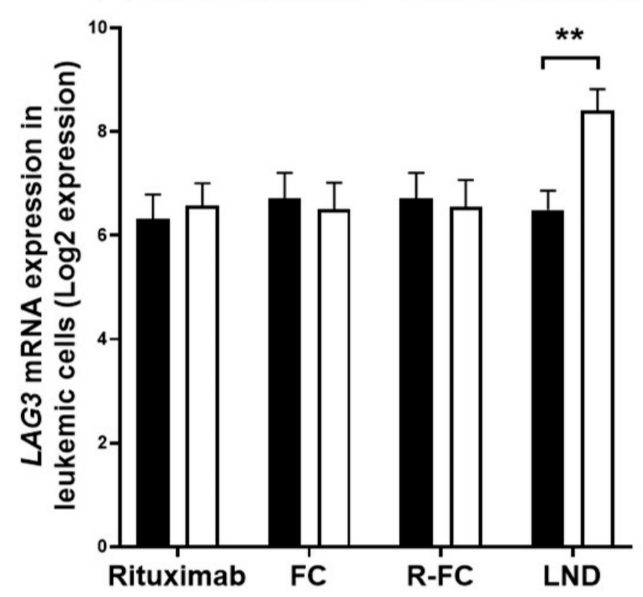

Figure 1. LAG-3 expression is upregulated on leukemic cells from patients with CLL. LAG-3 surface expression was evaluated on PBMCs from patients with CLL $(n=61)$ and HD $(n=20)$ by flow cytometry. (A) Representative dot plot for LAG-3+ CD19+ analysis; (B) Comparison of LAG-3 expression (MFI \pm SEM) between leukemic cells and B lymphocytes from HD; (C) Percentage of LAG-3+ leukemic cells compared to B cells from HD; (D) Sera levels of sLAG-3 were evaluated in 28 patients with CLL and $12 \mathrm{HD}$; (E) In silico analysis of the effect of the indicated therapies on LAG3 mRNA expression in leukemic cells. GSE112953 and GSE58211 from GEO database were included. Each dot represents an individual sample (FC: fludarabine-chlorambucil, R-FC: Rituximab- fludarabine-chlorambucil, LND: lenalidomide). ${ }^{* *} p<0.01$ and ${ }^{* * *} p<0.0001$. 


\subsection{LAG-3 Expression Correlates with Adverse Clinical Features and Poor Outcome in CLL}

Patients were next stratified by their cytogenetic alterations, revealing a diminished percentage of LAG-3+ leukemic cells in patients carrying del(13q) $(17.5 \% \pm 3.2 \mathrm{vs.} 26.7 \% \pm 3.8$, $p=0.02$ ) (Figure 2A). No significant differences were observed in those patients carrying adverse cytogenetics (patients with $\operatorname{del}(11 \mathrm{q}), \operatorname{del}(17 p)$ and/or trisomy 12 owing or not $\operatorname{del}(13 q))$ (Figure 2B) [38]. In silico analyses of RNAseq data from GEO database revealed that patients with ZAP70-CD38- (good prognosis) exhibited lower LAG3 mRNA levels than those expressing ZAP70 + CD38 + (poor prognosis) (Figure 2C).

As previously reported, increased LAG-3 expression was detected on leukemic cells from patients with unmutated IGHV (Figure 2D) [22]. Further, patients with del(13q) and unmutated IGHV displayed augmented LAG-3 expression compared to patients with $\operatorname{del}(13 q)$ and mutated status, suggesting that the levels of expression of this checkpoint mainly rely on mutational status rather than chromosomic alterations (Figure 2E,F). In addition, sLAG3 levels were also increased in patients with unmutated IGHV status (Figure 2G). Besides, in silico analyses using available data from the TCGA revealed that increased $L A G-3$ expression in leukemic cells was more abundant in patients bearing unfavorable mutations affecting NOTCH1 and MYD88 genes ( $p=0.01$ and $p=0.04$, respectively) (Figure 2H) [38]. Taken together, these findings suggest a higher dysregulation of LAG-3 expression on leukemic cells in patients with poor prognosis and unfavorable genetic and cytogenetic features.

\subsection{High LAG-3 Expression Is Associated with Shorter Time to Treatment and Poorer Overall Survival in CLL}

The impact of LAG-3 expression on survival was next evaluated. Noticeably, high LAG-3 surface expression on leukemic cells was associated with shorter time to treatment (TTT) (hazard risk $(\mathrm{HR})=2.4, p=0.05$ ) in our cohort (Figure 3A). In agreement, survival analysis using LAG3 mRNA expression from 107 patients with CLL (GSE22762 dataset) revealed diminished overall survival (OS) in patients with high $L A G 3$ expression ( $\mathrm{HR}=7.4$, $p<0.001$ ) (Figure 3B). The influence of $L A G 3$ and MHC class II genes on outcome in different hematological malignancies was further analyzed using the PRECOG tool. Z-score analysis, which allows direct comparison across different studies and platforms independently from timescale and range of predictor variables, revealed that $L A G 3$ axis has more influence on the clinical outcome of patients with CLL than in other hematological malignancies (Figure 3C). Altogether, these data highlight the importance of LAG-3 signaling in CLL and provides the rationale to further investigate this checkpoint as a possible therapeutic target in CLL.

\subsection{LAG-3 Expression Is Dysregulated on T and NK Cells and Affects Their Proliferation}

Surface LAG-3 expression on T and NK cells was next evaluated in 59 non-treated patients with CLL and $20 \mathrm{HD}$ by flow cytometry. LAG-3 surface expression on NK cells as well as percentage of LAG-3+ NK cells $(21.7 \% \pm 1.7 \mathrm{vs} .11 .4 \% \pm 1.6, p=0.0004)$ were significantly increased in patients (Figure 4A-C). LAG-3 levels were also elevated in total CD3+ T lymphocytes and CD8+ effector T cells, but it did not reach statistical significance in CD4+ T cells (MFI: $213.8 \pm 16.7$ vs. $151.3 \pm 8.3, p=0.02,290.1 \pm 23.5$ vs. $188.7 \pm 14.2$, $p=0.005$ and $176.7 \pm 17.78$ vs. $132.9 \pm 6.3, p=\mathrm{ns}$, respectively) (Figure $4 \mathrm{~A}, \mathrm{D}$ ). However, patients with CLL exhibited heightened percentage of both LAG-3+ CD4+ T cells $(16.3 \pm 1.3$ vs. $7.5 \pm 1.1, p=0.0001)$ and CD8+ T cells $(28.2 \pm 2.0$ vs. $11.9 \pm 1.5, p<0.0001)$ (Figure $4 \mathrm{E}$ ). Interestingly, percentage of LAG-3+ NK cells and CD4+ T cells positively correlated with LAG-3+ leukemic cells (Spearman's rank test $p=0.01$ and $p=0.03$, respectively). Likewise, percentage of LAG-3+ NK cells highly correlated with LAG-3+ CD4+ $(r=0.8, p<0.0001)$ and CD8+ T cells $(r=0.75, p<0.0001)$, thus suggesting a common mechanism regulating LAG-3 expression on these immune subsets. 

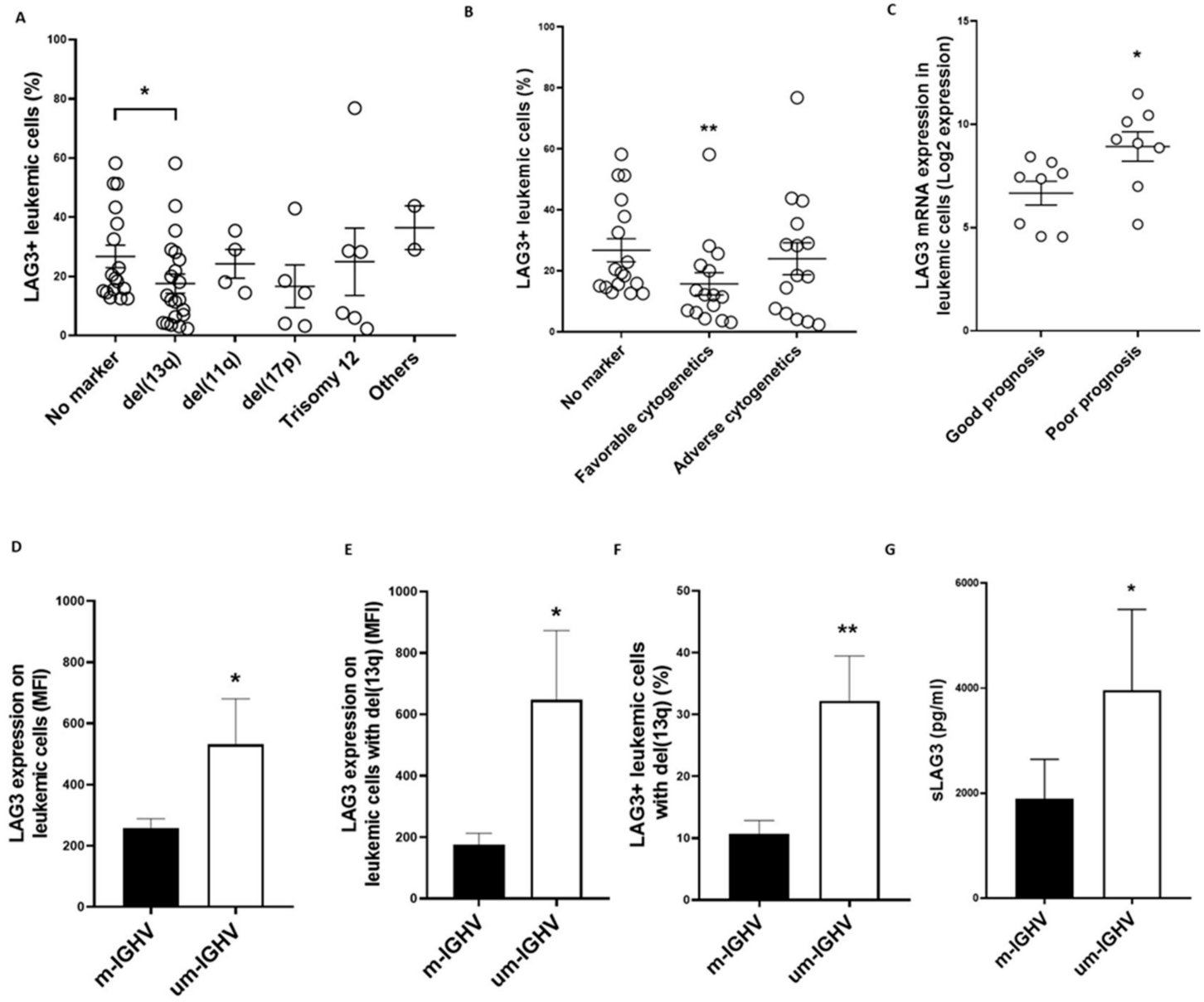

E
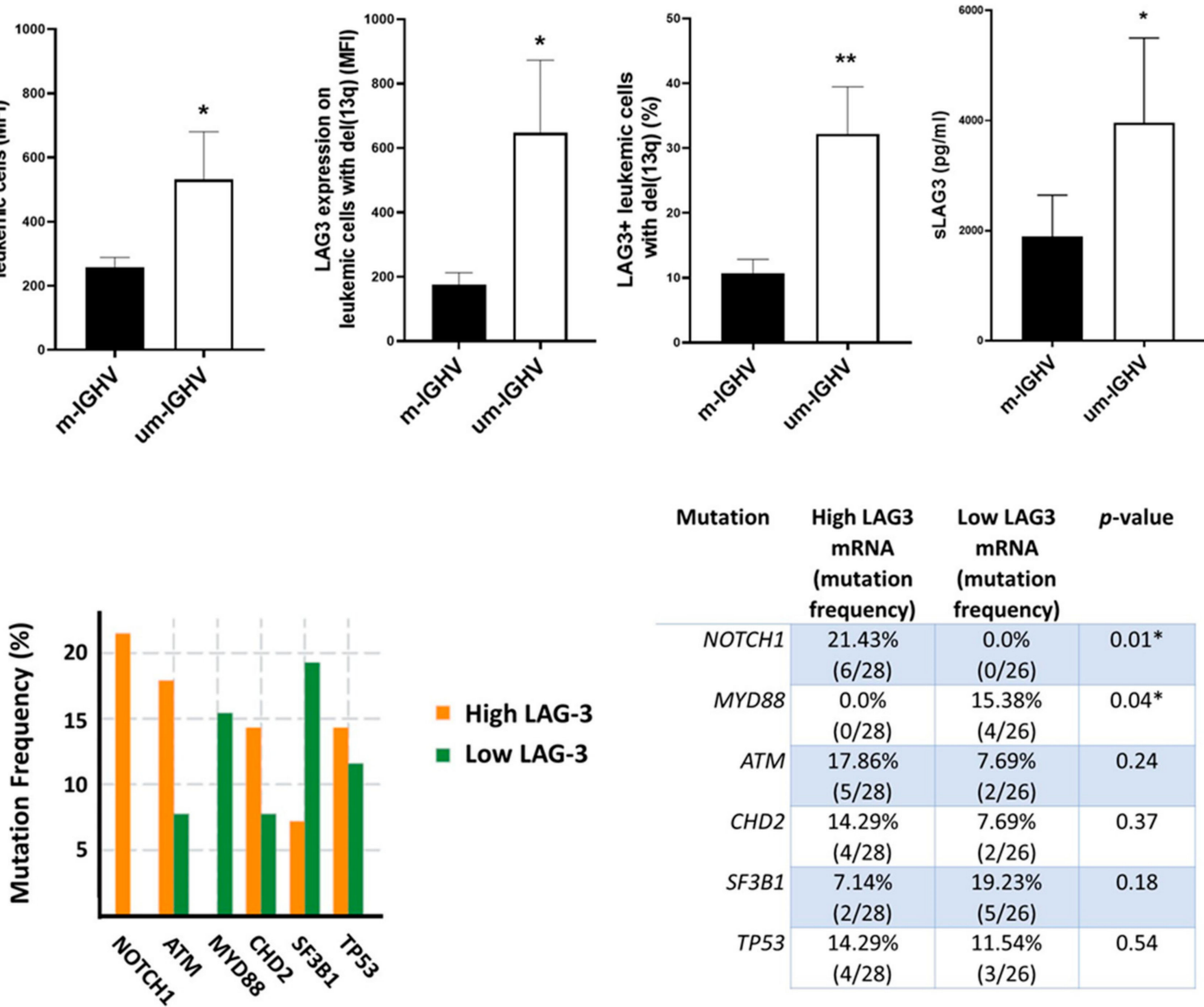

1. High LAG-3

- Low LAG-3

\begin{tabular}{|c|c|c|c|}
\hline Mutation & $\begin{array}{c}\text { High LAG3 } \\
\text { mRNA } \\
\text { (mutation } \\
\text { frequency) }\end{array}$ & $\begin{array}{l}\text { Low LAG3 } \\
\text { mRNA } \\
\text { (mutation } \\
\text { frequency) }\end{array}$ & $p$-value \\
\hline NOTCH1 & $\begin{array}{c}21.43 \% \\
(6 / 28)\end{array}$ & $\begin{array}{c}0.0 \% \\
(0 / 26)\end{array}$ & $0.01^{*}$ \\
\hline MYD88 & $\begin{array}{c}0.0 \% \\
(0 / 28)\end{array}$ & $\begin{array}{c}15.38 \% \\
(4 / 26)\end{array}$ & $0.04 *$ \\
\hline ATM & $\begin{array}{c}17.86 \% \\
(5 / 28)\end{array}$ & $\begin{array}{l}7.69 \% \\
(2 / 26)\end{array}$ & 0.24 \\
\hline $\mathrm{CHD} 2$ & $\begin{array}{l}14.29 \% \\
(4 / 28)\end{array}$ & $\begin{array}{l}7.69 \% \\
(2 / 26)\end{array}$ & 0.37 \\
\hline SF3B1 & $\begin{array}{l}7.14 \% \\
(2 / 28)\end{array}$ & $\begin{array}{c}19.23 \% \\
(5 / 26)\end{array}$ & 0.18 \\
\hline TP53 & $\begin{array}{c}14.29 \% \\
(4 / 28)\end{array}$ & $\begin{array}{c}11.54 \% \\
(3 / 26)\end{array}$ & 0.54 \\
\hline
\end{tabular}

Figure 2. LAG-3 expression correlates with prognostic factors in CLL. (A) LAG-3 surface expression was evaluated on leukemic cells from patients with CLL $(n=61)$ categorized by cytogenetics abnormalities by flow cytometry; (B) LAG-3 surface expression on leukemic cells in patients stratified by cytogenetics abnormalities $(n=61)$ : no marker (no abnormalities), favorable cytogenetics (del(13q)) and adverse cytogenetics (patients with del(11q), del(17p) and/or trisomy 12 owing or not del(13q)) is shown; (C) In silico analysis (GSE4392) of LAG3 mRNA expression in leukemic cells from ZAP70-CD38- (good prognosis) and ZAP70+CD38+ (poor prognosis) patients; (D-G) Evaluation of LAG-3 expression on leukemic cells from patients with mutated (m-IGHV) or unmutated (um-IGHV) IGHV; Comparison of LAG-3 expression patients $(\mathrm{MFI} \pm \mathrm{SEM})(\mathbf{E})$ and percentage $(\mathbf{F})$ in patients with del(13q) are shown $(n=61)$; $(\mathrm{G})$ Sera levels of sLAG-3 in 28 patients with mutated and unmutated IGHV status are depicted; $(\mathbf{H})$ In silico analysis of LAG3 mRNA expression in patients stratified by driver mutations in CLL using cBioportal. ${ }^{*} p<0.05$ and ${ }^{* *} p<0.01$. 


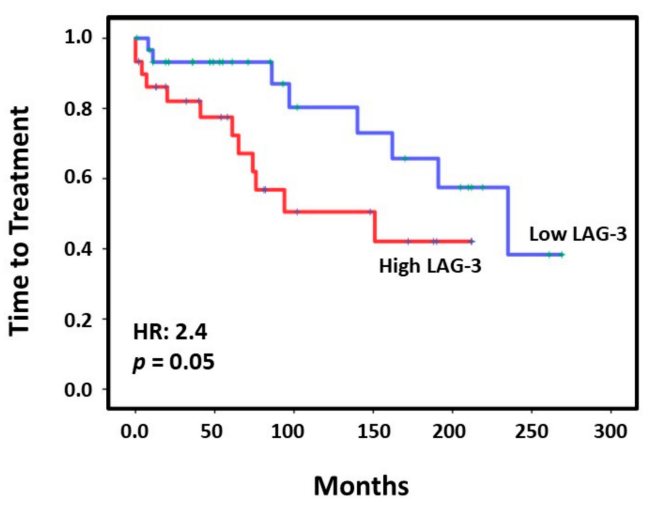

B

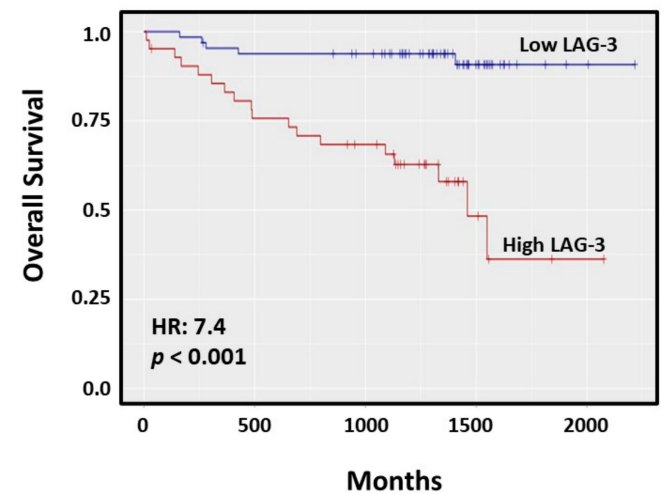

C

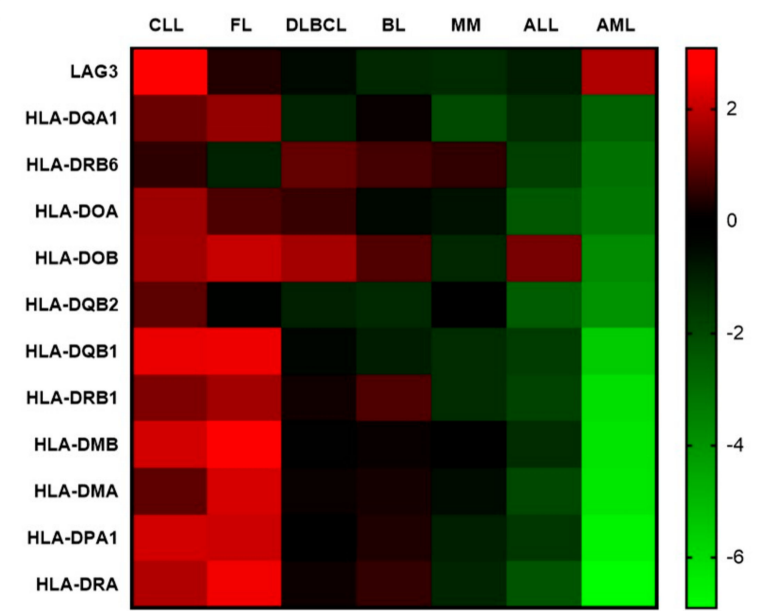

Figure 3. High LAG-3 expression on leukemic cells correlates with poor outcome in CLL. (A) Kaplan-Meier survival analysis relative to LAG-3 surface expression and TTT in 61 patients with CLL; (B) In silico analysis of OS in 107 patients with CLL using ShinyGeo online tool (GSE22762); (C) Heatmap representing z-score corresponding to the expression of $L A G 3$ and MHC class II genes and its influence in OS in diverse hematological malignancies analyzed by PRECOG tool (CLL: chronic lymphocytic leukemia; FL: follicular lymphoma; DLBCL: diffuse large B-cell lymphoma; BL: Burkitt leukemia/lymphoma; MM: multiple myeloma; ALL: acute lymphoblastic leukemia; AML: acute myeloid leukemia).

In order to evaluate the effect of increased LAG-3 expression on the above-mentioned immune subsets, PBMCs from 7 patients were treated with relatlimab (or control IgG) and stimulated with IL-2 for $72 \mathrm{~h}$. Relatlimab significantly boosted the proliferation of NK cells $(29.0 \pm 7$ vs. $15.3 \pm 1.7, p=0.03)$ and CD8+ effector T cells (27.69 \pm 11.7 vs. $12.5 \pm 2.2$, $p=0.04)$ without affecting leukemic cell proliferation $(2.7 \pm 0.8$ vs. $3.3 \pm 1.1)$ (Figure $4 \mathrm{~F}-\mathrm{J})$. These data suggest that LAG-3 exerts a co-inhibitory activity in NK cells and T cells from patients with CLL that may be reverted by relatlimab treatment.

\subsection{Relatlimab Induces Leukemic Cell Depletion and Enhances ADCC}

In order to evaluate the effect of LAG-3 blockade on leukemic cell count, PBMCs obtained from 26 patients with CLL were treated with relatlimab for 7 days. The antiLAG3 blocking mAb significantly reduced leukemic cell numbers compared to control IgG (Figure 5A). Interestingly, treatment with relatlimab reduced the expression of the anti-apoptotic protein Bcl-2, suggesting that LAG-3 blockade may impede pro-survival signaling in leukemic cells (Figure 5B). Further, combination of relatlimab with lenalidomide significantly increased the depletion of leukemic cells (Figure 5C). Despite no direct effect of LAG-3 blockade on NK cell-mediated cytotoxicity was observed, calcein-AM cytotoxicity assays revealed that combination of LAG-3 blockade and lenalidomide enhances rituximab-mediated ADCC activity of NK cells from patients with CLL (Figure 5D). Taken 
together, these data suggest that relatlimab, alone or in combination with lenalidomide, exhibit anti-leukemic activity that merits further investigations in CLL.

A
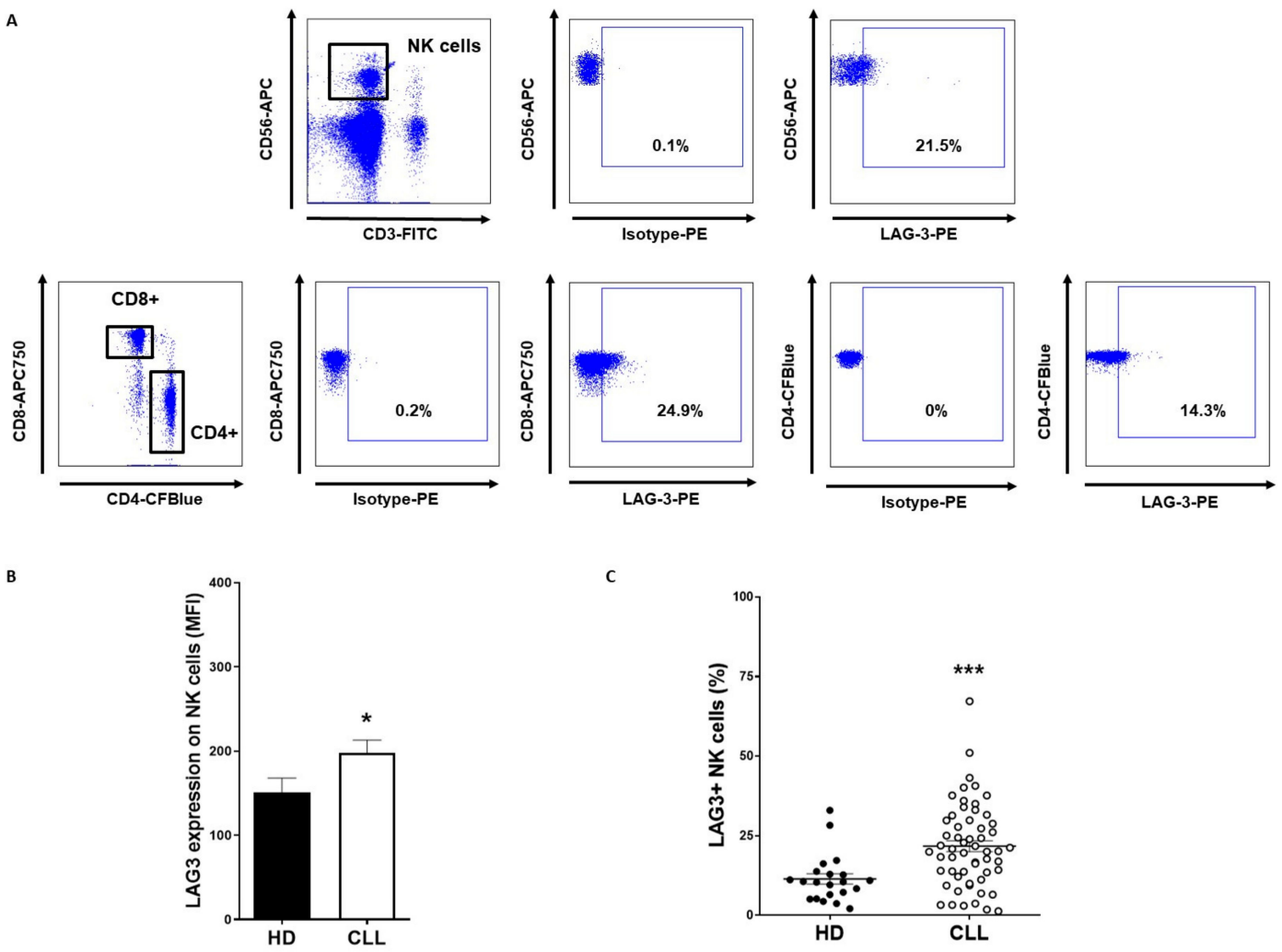

D

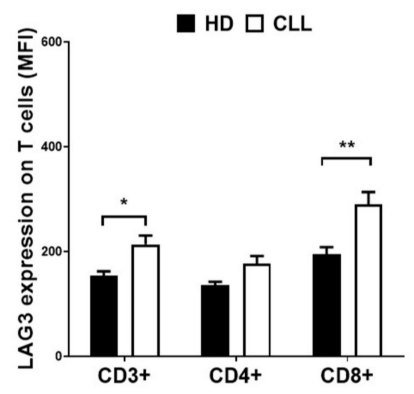

E
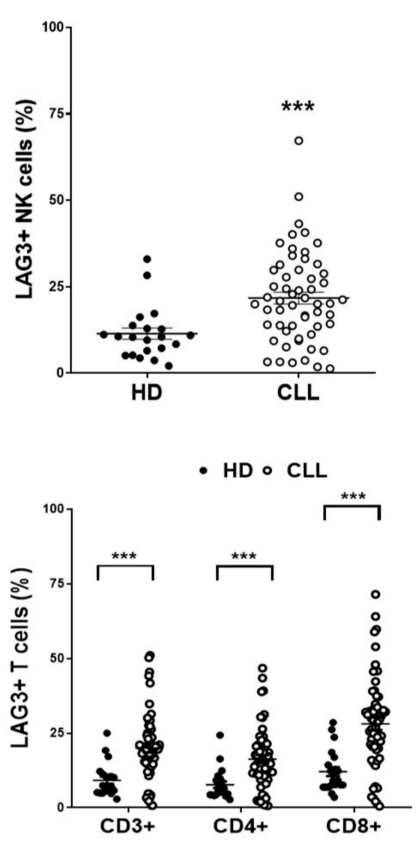
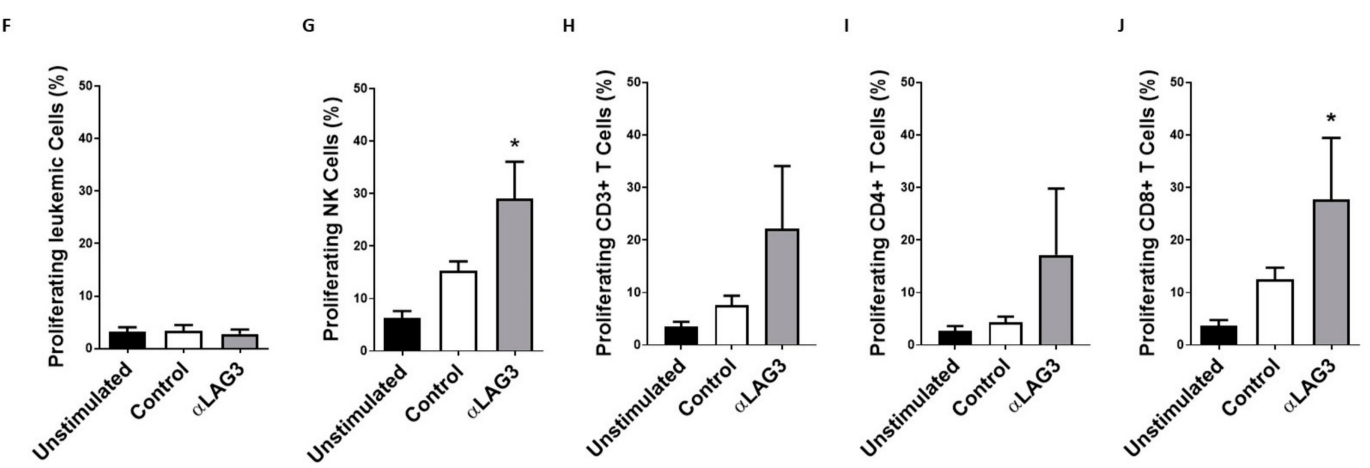

Figure 4. LAG-3 expression is increased on NK and T cells and induces immunosuppression. (A) Representative dot plots of percentage of LAG-3+ NK and CD8+ T cells in PBMCs from patients with CLL; LAG-3 surface expression was evaluated in 59 patients and 20 healthy donors in NK (B,C) and T cells $(\mathbf{D}, \mathbf{E})$ by flow cytometry. The graphs represent MFI \pm SEM and percentage of LAG-3+ cells; The effect of LAG-3 blockade with relatlimab or isotype control (Control; $10 \mu \mathrm{g} / \mathrm{mL}$ ) on the proliferation of leukemic cells (F), NK cells (G) or T cells (H-J) stimulated with $50 \mathrm{U} / \mathrm{mL}$ IL-2 was evaluated by CFSE staining and flow cytometry $(n=6){ }^{*} p<0.05,{ }^{* *} p<0.01$ and ${ }^{* * *} p<0.001$. 
A

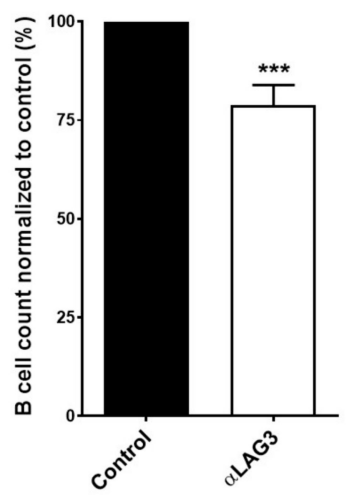

C

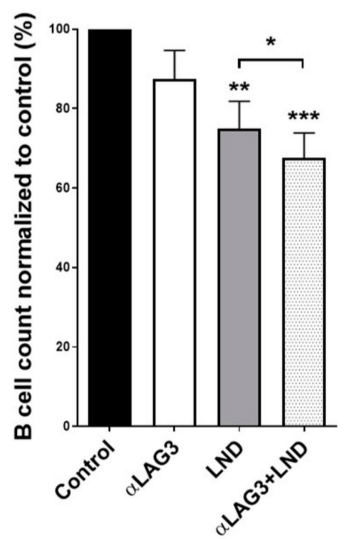

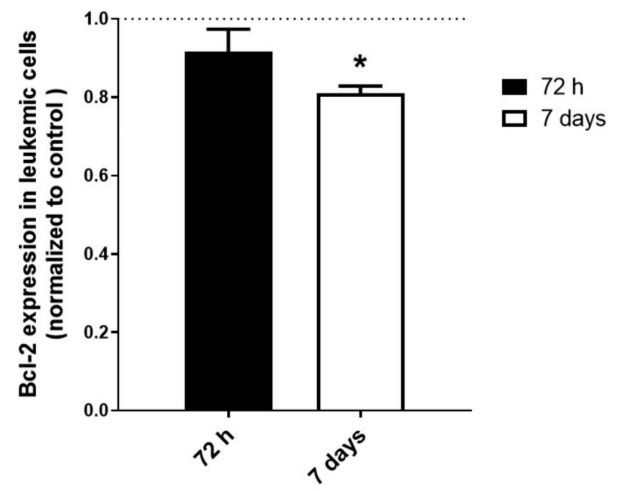

D

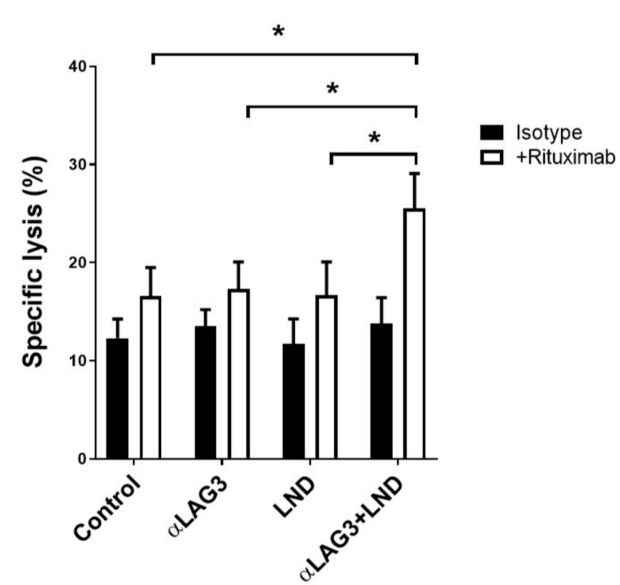

Figure 5. Treatment with relatlimab depletes leukemic cells. (A) PBMCs from 26 patients with CLL were treated with relatlimab or isotype control $(10 \mu \mathrm{g} / \mathrm{mL})$ and absolute leukemic cell count was performed at indicated timepoints. Bars represent the percentage of leukemic cells normalized to control; (B) Intracellular staining and flow cytometry analysis for Bcl-2 expression (normalized to control) were performed in PBMCs treated with relatlimab or isotype control $(10 \mu \mathrm{g} / \mathrm{mL})$ for $72 \mathrm{~h}$ or 7 days $(n=8)$; (C) Evaluation of absolute leukemic cell count (normalized to control) in PBMCs from patients treated with relatlimab or isotype control $(10 \mu \mathrm{g} / \mathrm{mL})$, alone or in combination with lenalidomide (LND) $(10 \mu \mathrm{M})$, for $72 \mathrm{~h}(n=12)$; (D) Effect of LAG-3 blockade on NK cell-mediated cytotoxicity was evaluated by calcein-AM assay in PBMCs from 10 patients treated with relatlimab $(10 \mu \mathrm{g} / \mathrm{mL})$, alone or in combination with lenalidomide (LND; $10 \mu \mathrm{M})$, and co-cultured with MEC-I CLL-derived cell line at 25:1 (E:T) ratio $(n=10)$ for $72 \mathrm{~h}$. ADCC was evaluated by pre-treating target MEC-I cells with rituximab $(10 \mu \mathrm{g} / \mathrm{mL}){ }^{*} p<0.05,{ }^{* *} p<0.01$ and ${ }^{* * *} p<0.001$.

\subsection{LAG-3 Blockade with Relatlimab Promotes Cytokine Production by T Cells}

PBMCs obtained from 11 patients with CLL were treated with relatlimab and $\mathrm{T}$ cell production of TNF- $\alpha$, IFN- $\gamma$ and IL-2 was measured by intracellular staining and flow cytometry analysis (Figure 6). LAG-3 blockade increased the percentage of TNF- $\alpha+$ CD4+ T cells. Lenalidomide significantly boosted TNF- $\alpha$ production by both CD4+ and CD8+ $\mathrm{T}$ cells, but no cooperative effect with LAG-3 blockade was observed. LAG-3 blockade also increased the percentage of IFN- $\gamma+\mathrm{CD} 8+\mathrm{T}$ cells $(41.3 \% \pm 6.9$ vs. $31.8 \% \pm 8.4$, $p=0.05)$, but no effect was observed upon lenalidomide treatment. Moreover, no effect on IFN- $\gamma$ production by NK cells was observed. Importantly, treatment with relatlimab increased the production of IL-2 by T lymphocytes and, specifically, by CD4+/CD8+ T cell subsets $(28.4 \% \pm 4.3$ vs. $22.1 \% \pm 4.8, p=0.003,35.0 \% \pm 5.5$ vs. $27.0 \% \pm 5.5, p=0.002$ and $18.2 \% \pm 3.7$ vs. $13.9 \% \pm 3.9, p=0.02$, respectively). Furthermore, the combination of LAG-3 blockade and lenalidomide significantly strengthened the increase of IL-2+ T cells. Altogether, these data indicate that LAG-3 may have a co-inhibitory activity in the 
regulation of cytokine production by T cells in CLL and LAG-3 blockade with relatlimab may, at least partially, restore this crippled $\mathrm{T}$ cell-mediated immune response.
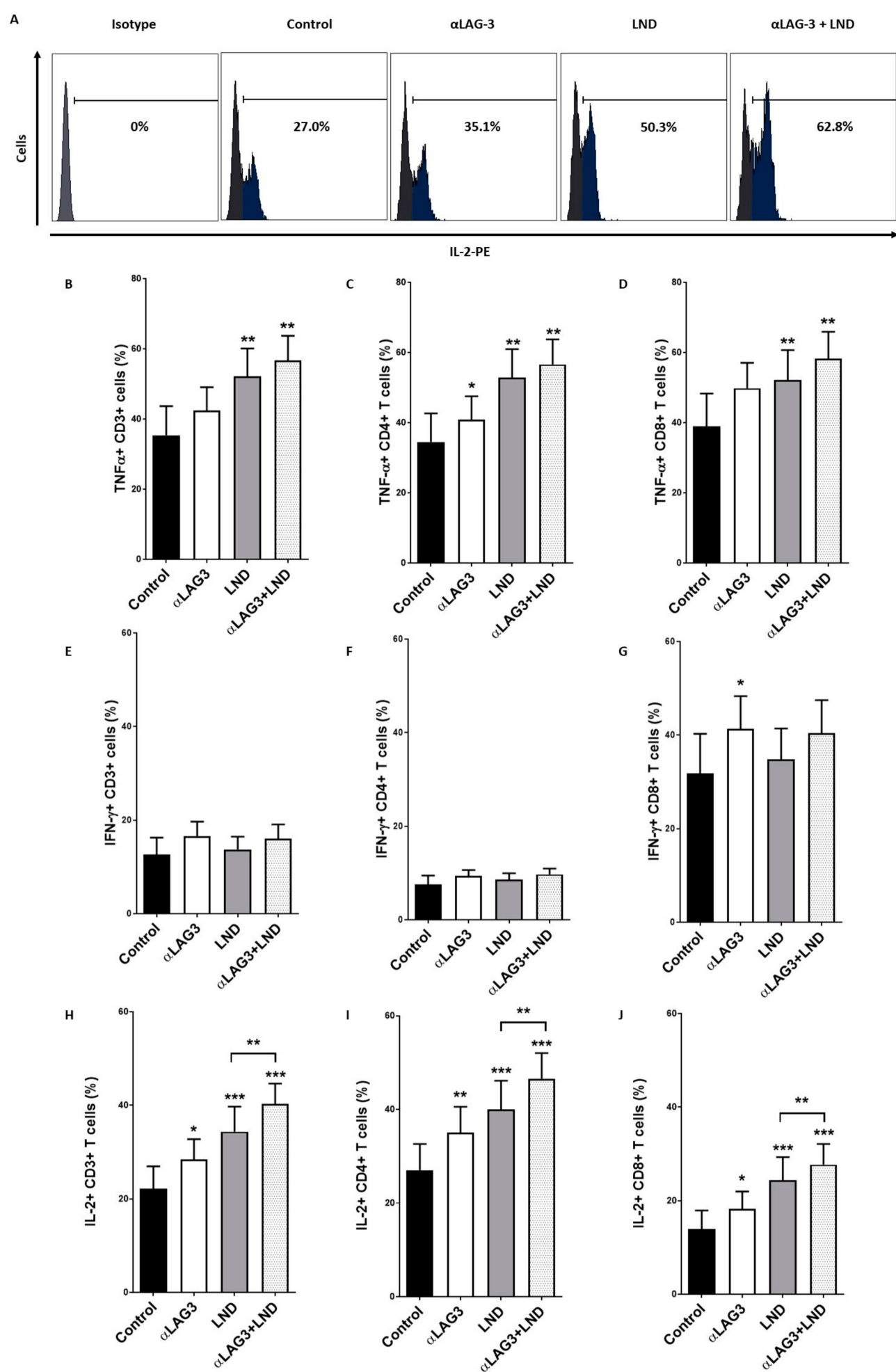

Figure 6. Relatlimab enhances cytokine production by T lymphocytes. (A) Representative histogram showing the effect of LAG-3 blockade, alone or in combination with lenalidomide, on IL-2 production by CD4+ T cells. (B-J) PBMCs from 11 patients with CLL were treated with relatlimab or isotype control $(10 \mu \mathrm{g} / \mathrm{mL})$, alone or in combination with lenalidomide (LND, $10 \mu \mathrm{M})$, for $72 \mathrm{~h}$. The percentage of T cells expressing TNF- $\alpha(\mathbf{B}-\mathbf{D})$, IFN- $\gamma(\mathbf{E}-\mathbf{G})$ and IL-2 (H-J) was evaluated by flow cytometry. ${ }^{*} p<0.05,{ }^{* *} p<0.01$ and ${ }^{* *} p<0.001$. 


\section{Discussion}

Recent advances with small molecule inhibitors, such as ibrutinib or venetoclax, have changed the landscape of management of patients with CLL. However, the arising resistance mechanisms associated with these therapies, together with the profound immunosuppression related to this disease, encourage the need for exploring new therapeutic alternatives. ICB-based therapies have prompted a major breakthrough in the treatment of cancer. Nonetheless, no clinical benefits have been achieved with anti-PD-1/PD-L1 blocking mAbs in CLL. In this context, novel checkpoint molecules, including LAG-3, NKG2A or ILT2, have been proposed as potential therapeutic targets in CLL [22,39-41].

LAG-3 is, along with PD-1/PD-L1 and CTLA-4, a promising target in cancer immunotherapy, since it plays a pivotal role in anti-tumor immunity [42]. LAG-3 blockade, alone or in combination with other ICBs, has demonstrated promising results in clinical trials $[17,19,42-44]$. Yet, little is known about the mechanisms of action underlying LAG-3 blockade in cancer [43]. Relatlimab, an anti-LAG-3 blocking $\mathrm{mAb}$, is currently one of the most advanced $\mathrm{mAbs}$ in clinical trials targeting solid tumors and hematological malignancies. Previous studies have reported the relevance of LAG-3/MHC-II in CLL pathology, highlighting this disease as a possible target for anti-LAG-3-based therapies. Our study confirms the profound dysregulation of LAG-3 expression on leukemic cells. Further, our data unveil that LAG-3 surface expression is decreased in patients with good prognostic features, such as those carrying del(13q) and mutated IGHV. Contrarily, LAG-3 expression is increased in patients with bad prognostic features, including unmutated IGHV, NOTCH1 or MYD88 mutations and ZAP70+CD38+ status. Accordingly, high LAG-3 surface expression correlated with shorter TTT in our cohort, and in silico analyses confirmed the poorer outcome in patients with high expression of LAG-3 and MHC-II genes in a larger set of patients with CLL. Importantly, heightened expression was also observed in T and NK cells, and LAG-3 expression on these immune subsets significantly correlated with LAG-3 expression on leukemic cells. Moreover, LAG-3 expression on NK cells highly correlated with LAG-3 expression on T cells, suggesting a common mechanism of regulation among leukemic and healthy immune cells. Altogether, these data highlight the dysregulation of LAG-3 on leukemic cells and provide new insights into the relevance of LAG-3 dysregulation in the clinical outcome of patients with CLL, hence suggesting that it may be involved in the suppression of the immune response in this malignancy.

To further analyze the therapeutic potential of targeting LAG-3 in CLL, we analyzed the anti-leukemic effect of relatlimab, an anti-LAG-3 blocking antibody currently ongoing clinical trials in CLL (ClinicalTrials.gov Identifier: NCT02061761), as well as the potential underlying mechanisms leading to anti-tumor responses in patients with CLL. Foremost, we demonstrate that relatlimab induces the depletion of leukemic cells ex vivo. Multiple underlying mechanisms may account for this anti-leukemic effect. Firstly, LAG-3 blockade may block the proposed sLAG-3 autocrine loop that promotes anti-apoptotic signaling upon engagement with MHC-II, which agrees with the decreased Bcl-2 expression observed in leukemic cells [22]. Secondly, our data reveal that LAG-3 has an immunosuppressive role in CLL, since LAG-3 sharply inhibited T and NK cell proliferation and cytokine production by $\mathrm{T}$ cells. Consequently, relatlimab was able to restore $\mathrm{T}$ and NK cell-mediated anti-tumor responses. LAG-3 blockade sharply increased NK and CD8+ T cell proliferation, as well as promoted production of IL-2 and other cytokines by T cells. Although LAG-3 blockade, along with IL-12 treatment, was shown to restore the anti-metastatic activity of NK cells in murine models of breast cancer, relatlimab did not directly induce NK cell-mediated cytotoxicity against leukemic cells. This is in line with previous reports, suggesting that LAG-3 do not play a direct role enhancing NK cell-mediated cytotoxicity [29,30,45]. In silico analysis showed that lenalidomide, but not rituximab or fludarabine-chlorambucil regimen, significantly increased LAG-3 expression on leukemic cells, suggesting that LAG-3 blockade may potentiate the anti-tumor effect of the immunomodulatory drug. These data agree with prior works from our group and others bringing to light that IMiDs may strengthen ICB-induced responses and NK cell-mediated cytotoxicity in CLL [40,46,47]. Accordingly, 
combination of LAG-3 blockade and lenalidomide cooperatively depleted leukemic cells in vitro. Further, treatment with relatlimab, in combination with lenalidomide, resulted in stimulated IL- 2 and IFN- $\gamma$ production by $\mathrm{T}$ cells and increased antibody-dependent cytotoxicity (ADCC). This effect may be associated with enhanced anti-leukemic responses mediated by NK and T cells. Overall, our data suggest that LAG-3 blockade may have a co-stimulatory effect in NK cell cytotoxicity, and combination of LAG-3 blockade with immunomodulatory drugs or cytokine treatment may increase NK cell-mediated cytotoxicity. The elucidation of additional costimulatory drugs potentiating LAG-3 blockade, and the effect of combining LAG-3 blockade with immunomodulatory drugs in other hematological malignancies typically displaying LAG-3 dysregulation, such as multiple myeloma, warrants further investigations [48-50].

In sum, our study confirms the profound alteration of LAG-3 expression and its clinical and immune relevance in CLL. Further, we provide new insights on the anti-leukemic potential of relatlimab, which may be related to decreased anti-apoptotic signaling in malignant cells, as well as enhanced NK and T cell-mediated responses.

Author Contributions: C.S.-B. designed and performed all the experiments, analyzed data, and wrote the manuscript; S.L.-H. performed experiments and analyzed data; Á.R.P. and E.G.-G. provided samples and clinical data; A.L.-S. designed experiments, supervised the research and the manuscript; A.P.G.-R. provided samples and clinical data, conceptualized the study, analyzed data, and supervised the manuscript; S.G. conceptualized the study, designed experiments, supervised the research, and wrote the manuscript. All authors have read and agreed to the published version of the manuscript.

Funding: This study was supported by the Spanish grant of Instituto de Salud Carlos III (PI19/01353) and FEDER European Union. CSB holds a Severo Ochoa Grant (BP19-066). The funders had no role in the study design, data collection, or analysis, the decision to publish, or the preparation of the manuscript.

Institutional Review Board Statement: The study was conducted according to the guidelines of the Declaration of Helsinki and approved by Comité de Ética de la Investigación del Principado de Asturias, case-19042016.

Informed Consent Statement: Informed consent was obtained from all subjects involved in the study.

Data Availability Statement: In silico analysis were performed from publicly available datasets from Gene Expression Omnibus (GEO) repository using ShinyGeo (https: / gdancik.shinyapps.io/ shinyGEO/ accessed on 8 January 2020) and RNAseq data from the TCGA database using cBioportal (cbioportal.org accessed on 12 December 2019).

Acknowledgments: The authors thank Bristol-Myers Squibb for kindly providing anti-LAG-3 blocking $\mathrm{mAb}$ (relatlimab) and Juan Ramón de los Toyos-González for providing control IgG.

Conflicts of Interest: The authors declare no conflict of interest.

\section{References}

1. Palmer, S.; Hanson, C.A.; Zent, C.S.; Porrata, L.F.; Laplant, B.; Geyer, S.M.; Markovic, S.N.; Call, T.G.; Bowen, D.A.; Jelinek, D.F.; et al. Prognostic importance of T and NK-cells in a consecutive series of newly diagnosed patients with chronic lymphocytic leukaemia. Br. J. Haematol. 2008, 141, 607-614. [CrossRef] [PubMed]

2. Huergo-Zapico, L.; Acebes-Huerta, A.; Gonzalez-Rodriguez, A.P.; Contesti, J.; Gonzalez-Garcia, E.; Payer, A.R.; Villa-Alvarez, M.; Fernandez-Guizan, A.; Lopez-Soto, A.; Gonzalez, S. Expansion of NK cells and reduction of NKG2D expression in chronic lymphocytic leukemia. Correlation with progressive disease. PLoS ONE 2014, 9, e108326. [CrossRef] [PubMed]

3. Wang, W.T.; Zhu, H.Y.; Wu, Y.J.; Xia, Y.; Wu, J.Z.; Wu, W.; Liang, J.H.; Wang, L.; Fan, L.; Li, J.Y.; et al. Elevated absolute NK cell counts in peripheral blood predict good prognosis in chronic lymphocytic leukemia. J. Cancer Res. Clin. Oncol. 2018, 144, 449-457. [CrossRef] [PubMed]

4. Hamblin, A.D.; Hamblin, T.J. The immunodeficiency of chronic lymphocytic leukaemia. Br. Med. Bull. 2008, 87, 49-62. [CrossRef]

5. Demaria, O.; Cornen, S.; Daeron, M.; Morel, Y.; Medzhitov, R.; Vivier, E. Harnessing innate immunity in cancer therapy. Nature 2019, 574, 45-56. [CrossRef]

6. Sordo-Bahamonde, C.; Vitale, M.; Lorenzo-Herrero, S.; Lopez-Soto, A.; Gonzalez, S. Mechanisms of Resistance to NK Cell Immunotherapy. Cancers 2020, 12, 893. [CrossRef] 
7. MacFarlane, A.W.t.; Jillab, M.; Smith, M.R.; Alpaugh, R.K.; Cole, M.E.; Litwin, S.; Millenson, M.M.; Al-Saleem, T.; Cohen, A.D.; Campbell, K.S. NK cell dysfunction in chronic lymphocytic leukemia is associated with loss of the mature cells expressing inhibitory killer cell Ig-like receptors. Oncoimmunology 2017, 6, e1330235. [CrossRef]

8. $\quad$ Riches, J.C.; Davies, J.K.; McClanahan, F.; Fatah, R.; Iqbal, S.; Agrawal, S.; Ramsay, A.G.; Gribben, J.G. T cells from CLL patients exhibit features of T-cell exhaustion but retain capacity for cytokine production. Blood 2013, 121, 1612-1621. [CrossRef]

9. Lorenzo-Herrero, S.; Lopez-Soto, A.; Sordo-Bahamonde, C.; Gonzalez-Rodriguez, A.P.; Vitale, M.; Gonzalez, S. NK Cell-Based Immunotherapy in Cancer Metastasis. Cancers 2018, 11, 29. [CrossRef]

10. Gonzalez-Rodriguez, A.P.; Villa-Alvarez, M.; Sordo-Bahamonde, C.; Lorenzo-Herrero, S.; Gonzalez, S. NK Cells in the Treatment of Hematological Malignancies. J. Clin. Med. 2019, 8, 1557. [CrossRef]

11. Ding, W.; LaPlant, B.R.; Call, T.G.; Parikh, S.A.; Leis, J.F.; He, R.; Shanafelt, T.D.; Sinha, S.; Le-Rademacher, J.; Feldman, A.L.; et al. Pembrolizumab in patients with CLL and Richter transformation or with relapsed CLL. Blood 2017, 129, 3419-3427. [CrossRef]

12. Do, P.; Beckwith, K.A.; Cheney, C.; Tran, M.; Beaver, L.; Griffin, B.G.; Mo, X.; Liu, Y.; Lapalombella, R.; Hertlein, E.; et al. Leukemic B Cell CTLA-4 Suppresses Costimulation of T Cells. J. Immunol. 2019, 202, 2806-2816. [CrossRef]

13. Kisielow, M.; Kisielow, J.; Capoferri-Sollami, G.; Karjalainen, K. Expression of lymphocyte activation gene 3 (LAG-3) on B cells is induced by T cells. Eur. J. Immunol. 2005, 35, 2081-2088. [CrossRef]

14. Andreae, S.; Buisson, S.; Triebel, F. MHC class II signal transduction in human dendritic cells induced by a natural ligand, the LAG-3 protein (CD223). Blood 2003, 102, 2130-2137. [CrossRef]

15. Baixeras, E.; Huard, B.; Miossec, C.; Jitsukawa, S.; Martin, M.; Hercend, T.; Auffray, C.; Triebel, F.; Piatier-Tonneau, D. Characterization of the lymphocyte activation gene 3-encoded protein. A new ligand for human leukocyte antigen class II antigens. J. Exp. Med. 1992, 176, 327-337. [CrossRef]

16. Merino, A.; Zhang, B.; Dougherty, P.; Luo, X.; Wang, J.; Blazar, B.R.; Miller, J.S.; Cichocki, F. Chronic stimulation drives human NK cell dysfunction and epigenetic reprograming. J. Clin. Investig. 2019, 129, 3770-3785. [CrossRef]

17. Maruhashi, T.; Sugiura, D.; Okazaki, I.M.; Okazaki, T. LAG-3: From molecular functions to clinical applications. J. Immunother Cancer 2020, 8. [CrossRef]

18. Wang, J.; Sanmamed, M.F.; Datar, I.; Su, T.T.; Ji, L.; Sun, J.; Chen, L.; Chen, Y.; Zhu, G.; Yin, W.; et al. Fibrinogen-like Protein 1 Is a Major Immune Inhibitory Ligand of LAG-3. Cell 2019, 176, 334-347.e12. [CrossRef]

19. Qi, Y.; Chen, L.; Liu, Q.; Kong, X.; Fang, Y.; Wang, J. Research Progress Concerning Dual Blockade of Lymphocyte-Activation Gene 3 and Programmed Death-1/Programmed Death-1 Ligand-1 Blockade in Cancer Immunotherapy: Preclinical and Clinical Evidence of This Potentially More Effective Immunotherapy Strategy. Front. Immunol. 2020, 11, 563258. [CrossRef]

20. Yang, Z.Z.; Kim, H.J.; Villasboas, J.C.; Chen, Y.P.; Price-Troska, T.; Jalali, S.; Wilson, M.; Novak, A.J.; Ansell, S.M. Expression of LAG-3 defines exhaustion of intratumoral PD-1(+) T cells and correlates with poor outcome in follicular lymphoma. Oncotarget 2017, 8, 61425-61439. [CrossRef]

21. Dama, P.; Tang, M.; Fulton, N.; Kline, J.; Liu, H. Gal9/Tim-3 expression level is higher in AML patients who fail chemotherapy. J. Immunother. Cancer 2019, 7, 175. [CrossRef]

22. Shapiro, M.; Herishanu, Y.; Katz, B.Z.; Dezorella, N.; Sun, C.; Kay, S.; Polliack, A.; Avivi, I.; Wiestner, A.; Perry, C. Lymphocyte activation gene 3: A novel therapeutic target in chronic lymphocytic leukemia. Haematologica 2017, 102, 874-882. [CrossRef]

23. Workman, C.J.; Vignali, D.A. Negative regulation of T cell homeostasis by lymphocyte activation gene-3 (CD223). J. Immunol. 2005, 174, 688-695. [CrossRef]

24. Gandhi, M.K.; Lambley, E.; Duraiswamy, J.; Dua, U.; Smith, C.; Elliott, S.; Gill, D.; Marlton, P.; Seymour, J.; Khanna, R. Expression of LAG-3 by tumor-infiltrating lymphocytes is coincident with the suppression of latent membrane antigen-specific CD8+ T-cell function in Hodgkin lymphoma patients. Blood 2006, 108, 2280-2289. [CrossRef]

25. Woo, S.R.; Turnis, M.E.; Goldberg, M.V.; Bankoti, J.; Selby, M.; Nirschl, C.J.; Bettini, M.L.; Gravano, D.M.; Vogel, P.; Liu, C.L.; et al. Immune inhibitory molecules LAG-3 and PD-1 synergistically regulate T-cell function to promote tumoral immune escape. Cancer Res. 2012, 72, 917-927. [CrossRef]

26. Que, Y.; Fang, Z.; Guan, Y.; Xiao, W.; Xu, B.; Zhao, J.; Chen, H.; Zhang, X.; Zeng, M.; Liang, Y.; et al. LAG-3 expression on tumor-infiltrating $T$ cells in soft tissue sarcoma correlates with poor survival. Cancer Biol. Med. 2019, 16, 331-340. [CrossRef]

27. Solinas, C.; Migliori, E.; De Silva, P.; Willard-Gallo, K. LAG3: The Biological Processes That Motivate Targeting This Immune Checkpoint Molecule in Human Cancer. Cancers 2019, 11, 1213. [CrossRef]

28. Zhou, G.; Noordam, L.; Sprengers, D.; Doukas, M.; Boor, P.P.C.; van Beek, A.A.; Erkens, R.; Mancham, S.; Grunhagen, D.; Menon, A.G.; et al. Blockade of LAG3 enhances responses of tumor-infiltrating T cells in mismatch repair-proficient liver metastases of colorectal cancer. Oncoimmunology 2018, 7, e1448332. [CrossRef]

29. Huard, B.; Tournier, M.; Triebel, F. LAG-3 does not define a specific mode of natural killing in human. Immunol. Lett. 1998, 61, 109-112. [CrossRef]

30. Miyazaki, T.; Dierich, A.; Benoist, C.; Mathis, D. Independent modes of natural killing distinguished in mice lacking Lag3. Science 1996, 272, 405-408. [CrossRef]

31. Gestermann, N.; Saugy, D.; Martignier, C.; Tille, L.; Fuertes Marraco, S.A.; Zettl, M.; Tirapu, I.; Speiser, D.E.; Verdeil, G. LAG-3 and PD-1+LAG-3 inhibition promote anti-tumor immune responses in human autologous melanoma/T cell co-cultures. Oncoimmunology 2020, 9, 1736792. [CrossRef] [PubMed] 
32. Puhr, H.C.; Ilhan-Mutlu, A. New emerging targets in cancer immunotherapy: The role of LAG3. ESMO Open 2019, 4, e000482. [CrossRef] [PubMed]

33. Dumas, J.; Gargano, M.A.; Dancik, G.M. shinyGEO: A web-based application for analyzing gene expression omnibus datasets. Bioinformatics 2016, 32, 3679-3681. [CrossRef] [PubMed]

34. Gentles, A.J.; Newman, A.M.; Liu, C.L.; Bratman, S.V.; Feng, W.; Kim, D.; Nair, V.S.; Xu, Y.; Khuong, A.; Hoang, C.D.; et al. The prognostic landscape of genes and infiltrating immune cells across human cancers. Nat. Med. 2015, 21, 938-945. [CrossRef]

35. Cerami, E.; Gao, J.; Dogrusoz, U.; Gross, B.E.; Sumer, S.O.; Aksoy, B.A.; Jacobsen, A.; Byrne, C.J.; Heuer, M.L.; Larsson, E.; et al. The cBio cancer genomics portal: An open platform for exploring multidimensional cancer genomics data. Cancer Discov. 2012, 2, 401-404. [CrossRef]

36. Sordo-Bahamonde, C.; Lorenzo-Herrero, S.; Gonzalez, S.; Lopez-Soto, A. A cytofluorimetric assay to evaluate intracellular cytokine production by NK cells. Methods Enzymol. 2020, 631, 343-355. [CrossRef]

37. Lorenzo-Herrero, S.; Sordo-Bahamonde, C.; Gonzalez, S.; Lopez-Soto, A. Evaluation of NK cell cytotoxic activity against malignant cells by the calcein assay. Methods Enzymol. 2020, 631, 483-495. [CrossRef]

38. Gonzalez-Rodriguez, A.P.; Payer, A.R.; Menendez-Suarez, J.J.; Sordo-Bahamonde, C.; Lorenzo-Herrero, S.; Zanabili, J.; Fonseca, A.; Gonzalez-Huerta, A.J.; Palomo, P.; Gonzalez, S. Driver Mutations and Single Copy Number Abnormalities Identify Binet Stage A Patients with Chronic Lymphocytic Leukemia with Aggressive Progression. J. Clin. Med. 2020, 9, 3695. [CrossRef]

39. McWilliams, E.M.; Mele, J.M.; Cheney, C.; Timmerman, E.A.; Fiazuddin, F.; Strattan, E.J.; Mo, X.; Byrd, J.C.; Muthusamy, N.; Awan, F.T. Therapeutic CD94/NKG2A blockade improves natural killer cell dysfunction in chronic lymphocytic leukemia. Oncoimmunology 2016, 5, e1226720. [CrossRef]

40. Villa-Alvarez, M.; Sordo-Bahamonde, C.; Lorenzo-Herrero, S.; Gonzalez-Rodriguez, A.P.; Payer, A.R.; Gonzalez-Garcia, E.; Villa-Alvarez, M.C.; Lopez-Soto, A.; Gonzalez, S. Ig-Like Transcript 2 (ILT2) Blockade and Lenalidomide Restore NK Cell Function in Chronic Lymphocytic Leukemia. Front. Immunol. 2018, 9, 2917. [CrossRef]

41. Villa-Alvarez, M.; Lorenzo-Herrero, S.; Gonzalez-Rodriguez, A.P.; Lopez-Soto, A.; Payer, A.R.; Gonzalez-Garcia, E.; HuergoZapico, L.; Gonzalez, S. Ig-like transcript 2 (ILT2) suppresses T cell function in chronic lymphocytic leukemia. Oncoimmunology 2017, 6, e1353856. [CrossRef]

42. Lecocq, Q.; Keyaerts, M.; Devoogdt, N.; Breckpot, K. The Next-Generation Immune Checkpoint LAG-3 and Its Therapeutic Potential in Oncology: Third Time's a Charm. Int. J. Mol. Sci. 2020, 22, 75. [CrossRef]

43. Graydon, C.G.; Mohideen, S.; Fowke, K.R. LAG3's Enigmatic Mechanism of Action. Front. Immunol. 2020, 11, 615317. [CrossRef]

44. Shan, C.; Li, X.; Zhang, J. Progress of immune checkpoint LAG-3 in immunotherapy. Oncol. Lett. 2020, 20, 207. [CrossRef]

45. Ohs, I.; Ducimetiere, L.; Marinho, J.; Kulig, P.; Becher, B.; Tugues, S. Restoration of Natural Killer Cell Antimetastatic Activity by IL12 and Checkpoint Blockade. Cancer Res. 2017, 77, 7059-7071. [CrossRef]

46. Gorgun, G.; Samur, M.K.; Cowens, K.B.; Paula, S.; Bianchi, G.; Anderson, J.E.; White, R.E.; Singh, A.; Ohguchi, H.; Suzuki, R.; et al. Lenalidomide Enhances Immune Checkpoint Blockade-Induced Immune Response in Multiple Myeloma. Clin. Cancer Res. 2015, 21, 4607-4618. [CrossRef]

47. Acebes-Huerta, A.; Huergo-Zapico, L.; Gonzalez-Rodriguez, A.P.; Fernandez-Guizan, A.; Payer, A.R.; Lopez-Soto, A.; Gonzalez, S. Lenalidomide induces immunomodulation in chronic lymphocytic leukemia and enhances antitumor immune responses mediated by NK and CD4 T cells. Biomed. Res. Int. 2014, 2014, 265840. [CrossRef]

48. Fabienne, L.; Pennell, M.; Benson, D.M., Jr.; Efebera, Y.; Chaudhry, M.; Woyach, J.A.; Guan, X.; Suohui, Z.; Burd, C.E.; Rosko, A.E. Exploring LAG-3 Expression in Multiple Myeloma Patients Following Autologous Stem Cell Transplant. Blood 2018, 132, 3434. [CrossRef]

49. Mussetti, A.; Pellegrinelli, A.; Cieri, N.; Garzone, G.; Dominoni, F.; Cabras, A.; Montefusco, V. PD-L1, LAG3, and HLA-DR are increasingly expressed during smoldering myeloma progression. Ann. Hematol. 2019, 98, 1713-1720. [CrossRef]

50. Lucas, F.; Pennell, M.; Huang, Y.; Benson, D.M.; Efebera, Y.A.; Chaudhry, M.; Hughes, T.; Woyach, J.A.; Byrd, J.C.; Zhang, S.; et al. T Cell Transcriptional Profiling and Immunophenotyping Uncover LAG3 as a Potential Significant Target of Immune Modulation in Multiple Myeloma. Biol. Blood Marrow Transplant. 2020, 26, 7-15. [CrossRef] 